\title{
Research on Dynamic Balance of Spindle Rotor System Based on Particle Swarm Optimization
}

\author{
Zhan Wang, ${ }^{1}$ Dongzheng Li, ${ }^{1}$ Zinan Wang $\mathbb{D}^{1},{ }^{1}$ Aoxiang Liu, ${ }^{1,2}$ and Ruiyao Tao ${ }^{1}$ \\ ${ }^{1}$ School of Mechanical Engineering, Shenyang Jianzhu University, Shenyang 110168, China \\ ${ }^{2}$ North Huajin Chemical Industries Group Corporation, Panjin 124000, China \\ Correspondence should be addressed to Zinan Wang; wzn1404589743@126.com
}

Received 24 October 2021; Accepted 7 December 2021; Published 20 December 2021

Academic Editor: Georgios I. Giannopoulos

Copyright (c) 2021 Zhan Wang et al. This is an open access article distributed under the Creative Commons Attribution License, which permits unrestricted use, distribution, and reproduction in any medium, provided the original work is properly cited.

The dynamic balance is a significant issue for the nonlinear dynamic characteristics of the spindle rotor system. However, there is a problem that the dynamic balance is lacking detailed study on optimization method. In the paper, a modal dynamic balance optimization model of spindle rotor system is proposed, which can intend to improve the accuracy of spindle rotor system modal dynamic balance. Because the multiorder unbalance components are the main spindle rotor system mode shapes, the particle swarm optimization (PSO) method is adopted. The sum of squares of residual vibration after balancing is taken as the optimization objective, and the correction is presented as the optimization variable in the optimization model. The optimal correction weight of every unbalance component is calculated through a modal matrix equation of PSO. The vibration amplitude that is greatly reduced after optimization balance is presented under different conditions. The balancing effect shows a better dynamic characteristic than that of traditional methods. And the fluctuation range of the axis track of the rotor system also shows reductive phenomenon. The proposed optimization spindle rotor system model is well verified through experiments. It can contribute a theoretical optimization foundation for available dynamic balance in spindle rotor system.

\section{Introduction}

Rotor system dynamic output characteristics determine the precision machining of aerospace, petrochemical, high speed railway, and other fields. In the study of rotor system dynamic characteristics, the dynamic unbalance is one of the most important subjects that can influence the stability problem [1-3]. When the spindle unit is running for a long time, the spindle will produce unbalanced force and vibration due to wear and deformation [4]. The instability of rotor system is prominent at high speed. In particular, when the speed of spindle is close to the critical speed, the deflection deformation of the spindle rotor system will aggravate the influence of unbalanced vibration and may seriously result in the damage of the spindle.

Many efforts have been made to study the efficiency and method of the spindle rotor system dynamic balance, aiming to solve the stability of the dynamic output problem. The key issue in spindle rotor system can improve the dynamic balance effect through some optimization method. Zhang and Zhang [5] proposed a total phase difference maximizing method which can select the actual axial position in the rigid rotor system. Huang et al. [6] presented a novel double-plane balancing method to balance the rotor system through transient amplitudes; the balancing efficiency can be improved greater than traditional steady-state modal method. Wen et al. [7] developed a rotor transient method of modal balance based on empirical mode decomposition theory, and the rotor system could pass the critical resonance region smoothly through adding reasonable trial weight. Chen et al. [8] gave a specific explanation of the periodic solution and quasi-periodic solution of the system through combining multiple harmonic balance method with Runge-Kutta method. The nonlinear dynamic characteristics of rotor system were revealed under double excitation. Deepthikumar et al. [9] demonstrated the analysis of the modeling rotor system unbalances whose eccentricity polynomial function was considered, and the correction balance mass was 
calculated at critical speed. Besides, it has been showed that transient force of balance disc can be predicted directly by the vibration characteristics of the rotor system based on the Newmark method [10]. Bin et al. [11] investigated unbalance excitation effect on the rotor system dynamic balance. Reasonable balancing plane number and places of rotors were adjusted through the least squares method. The results indicated that the novel balancing method of flexible rotor system could improve efficiency.

In fact, it is far from enough to just analyze the dynamic balance of traditional method in spindle rotor system. Due to the nonlinear dynamic characteristics in high speed condition, some algorithm methods need to be used in the performance of rapidly suppressing vibration. Some relevant optimization and suppression vibration phenomena methods were also widely observed in rotor system. Tao et al. [12] adapted a particle swarm optimization algorithm based on multiscale adaptive cooperative mutation strategy to improve the accuracy of final calculation, and the global solution has also been analyzed. Yun et al. [13] established the optimization variables and individual fitness function based particle swarm optimization and modeled the optimization finite element model of rotor system which can suppress vibration effectively. Max et al. [14] proposed a modal weighted optimization method for evaluating residual modal unbalance. They found that the residual modal unbalances have an obvious effect on rotor system balancing facilities. Li et al. [15] developed a modal dynamic balance method for high speed flexible rotor without trial weight, and the unbalance amount and azimuth of rotor system were rapidly obtained by the optimized method. Díaz et al. [16] proposed a novel method which could find the real modes of the rotor system through the coordinate transformation, which resulted in that the optimum extraction position of the balancing parameters can be determined. Besides, it has been demonstrated that the stability and efficiency of rotor system dynamic balancing could be improved through PSO algorithm [17-19].

However, as can be seen from the knowledge of the previous references, less research is related to the multiorder unbalance components. In order to analyze the dynamic balance effect on the spindle rotor system vibration, in the paper, the modal dynamic balance optimization model is adapted. Since this paper takes the sum of squares of residual vibration after balancing as the optimization objective, considering multiorder unbalance components, the correction parameters of each order after modal balance of spindle rotor system are optimized through particle swarm optimization algorithm. Then, the optimal compensation amount of each order of unbalance components is achieved, which is employed to suppress unbalanced vibration effectively. A specific study is performed on the influence of the rotor system nonlinear dynamic behavior, which offers a theoretical optimization foundation for available dynamic balance in spindle rotor system.

\section{Modal Balance Method Based on Particle Swarm Optimization}

2.1. Modal Balance Method. Combined with the dynamics theory of spindle rotor system, the rotor system can be divided into several unbalanced components, and each component corresponds to respective main mode. The modal balance method can balance the unbalanced components separately. Spindle needs dynamic balance to keep rotor system in balance. Thus, the resonance field can be avoided when the rotation speed reaches critical speed. The force diagram of spindle rotor system is shown in Figure 1. $k_{1}$ and $k_{2}$ are the stiffness of the front and rear bearings, and $c_{1}$ and $c_{2}$ are the damping of the front and rear bearings, respectively.

Assuming that the unbalanced force on the spindle rotor system is $F(z)$, the vibration differential equation of the motorized spindle is shown in the following equation [20]:

$$
\begin{aligned}
M \ddot{x}(z)+C \dot{x}(z)+K x(z) & =F(z), \\
x(z) & =X e^{s z},
\end{aligned}
$$

where $M$ is the mass matrix, $C$ is the damping matrix, $K$ is the stiffness matrix, $x(z)$ is the vibration vector of the spindle rotor system, and $X$ is the amplitude of vibration.

The natural frequency of the spindle is multiorder in the process of rotation, and every vibration mode is orthogonal to the others. The orthogonal expression is shown in the following equation:

$$
\int_{0}^{l} m \xi_{i}(z) \xi_{j}(z) d z= \begin{cases}0, & (i \neq j) \\ N_{j}, & (i=j)\end{cases}
$$

where $\xi$ is the mass matrix of characteristic function, $N_{j}$ is the modal mass the $j_{\text {th }}$ mode, and $m$ is mass of the rotor system.

The unbalance force of spindle rotor system is directly related to characteristic function, mass, and other parameters; the unbalanced force is shown in the following equation:

$$
\begin{aligned}
F(z) & =\Omega^{2} \sum_{j=1}^{\infty} c_{j} m(z) \xi_{j}(z), \\
c_{j} & =c_{j} e^{i a_{j}}
\end{aligned}
$$

where $c_{j}$ is the $j_{\text {th }}$ mode component contained in the eccentricity distribution, $a_{j}$ is the azimuth of the component, and $\Omega$ is the speed of the spindle rotor system.

The vibration curve of the spindle rotor system can be regarded as the superposition of the main vibration modes of each order generated, which is shown in the following equation:

$$
\begin{array}{r}
a_{j}=A_{j}(\Omega) c_{j}, \\
A_{j}(\Omega)=\frac{\Omega^{2}}{\lambda_{j}^{2}-\Omega_{2}},
\end{array}
$$


where $A_{j}(\Omega)$ is the dynamic method coefficient of spindle rotor system.

Assuming that the spindle reaches balance, the support reaction force of the rotor system is shown in the following equation:

$$
\left\{\begin{array}{l}
F_{\mathrm{A}}=\frac{\Omega^{2}}{l}\left[\int_{0}^{l} z m(z) \varphi d z+\int_{0}^{l} z F(z) d z+\sum_{k=1}^{K} z_{k} Q_{k}\right], \\
F_{\mathrm{B}}=\frac{\Omega^{2}}{l}\left[\int_{0}^{l}(l-z) m(z) \varphi d z+\int_{0}^{l}(l-z) F(z) d z+\sum_{k=1}^{K}\left(l-z_{k}\right) Q_{k}\right], \\
F_{\mathrm{A}}+F_{\mathrm{B}}=\Omega^{2}\left[\int_{0}^{l} m(z) \varphi d z+\int_{0}^{l} F(z) d z+\sum_{k=1}^{K} Q_{k}\right],
\end{array}\right.
$$

where $Q$ is the corrected mass of the spindle rotor system, $F_{\mathrm{A}}$ and $F_{\mathrm{B}}$ are the supporting reaction force of the rotor system, and $\varphi$ is the vibration of the spindle rotor system.

The relationship of the unbalance of the spindle rotor system and the correction quality is shown in the following equation:

$$
\left[\begin{array}{cccc}
\xi_{1} & \xi_{1} & \cdots & \xi_{1} \\
\xi_{2} & \xi_{2} & \cdots & \xi_{2} \\
\vdots & \vdots & \ddots & \vdots \\
\xi_{m} & \xi_{m} & \cdots & \xi_{m}
\end{array}\right]\left[\begin{array}{cccc}
Q_{1} & Q_{2} & \cdots & Q_{n} \\
Q_{1} & Q_{2} & \cdots & Q_{n} \\
\vdots & \vdots & \ddots & \vdots \\
Q_{1} & Q_{2} & \cdots & Q_{n}
\end{array}\right]=\left[\begin{array}{c}
F_{1}(z) \\
F_{2}(z) \\
\vdots \\
F_{m}(z)
\end{array}\right] .
$$

\subsection{Modal Balance Method Based on Particle Swarm} Optimization. The PSO algorithm is a global random search algorithm based on swarm intelligence, which is proposed by simulating the migration and clustering behavior of bird swarms during foraging. The PSO treats a counterweight block as a particle and all counterweight blocks as a particle swarm. The position of each counterweight in the $\mathrm{N}$-dimensional space can represent its weight, which can be regarded as a feasible solution. The flight process of the counterweight in the $\mathrm{N}$-dimensional space is the search process. The counterweight changes the flight speed continuously, and then the position changes continuously until the iteration conditions are satisfied or the global optimal solution is obtained. The relationship between the speed of the counterweight block and the changed position is shown in the following equation:

$$
\begin{aligned}
V_{\mathrm{id}}= & \omega V_{\mathrm{id}}+C_{1} \operatorname{random}(0,1)\left(p_{\mathrm{id}}-X_{\mathrm{id}}\right), \\
& +C_{2} \operatorname{random}(0,1)\left(p_{\mathrm{gd}}-X_{\mathrm{id}}\right), \\
X_{\mathrm{id}}= & X_{\mathrm{id}}+V_{\mathrm{id}},
\end{aligned}
$$

where $\omega$ is an inertial factor, its value is less than $0, C_{1}$ is the individual learning factor, $C_{2}$ is the population learning factor, $C_{1}, C_{2}$ are constant, usually defined as $C_{1}=C_{2}=2$, random $(0,1)$ is a random number on $[0,1], p_{\mathrm{id}}$ is the optimal position of each particle in $N$-dimensional space, and $p_{\text {gd }}$ is the global optimal position.
The square sum of the residual vibration $\delta$ of the modal balance method is used as the fitness function in the particle swarm calculation process, and the correction mass during balancing cannot exceed the maximum mass allowed by the correction plane, and the fitness function of the algorithm is shown in the following equation:

$$
\left\{\begin{array}{l}
f(x)=|\delta|^{2}, \\
\delta=\xi Q+F,
\end{array}\right.
$$

where $Q$ is the maximum mass allowed for the correction plane.

The operation process of the particle swarm algorithm is as follows, and the flowchart of particle swarm algorithm is shown in Figure 2.

(1) $N$ sets of counterweight masses are randomly generated as the initial solution, which is the initial population of the particle swarm algorithm.

(2) 2 random numbers are randomly generated as the flying speed and distance of the weight mass.

(3) The fitness function corresponding to the weight of each group is calculated.

(4) The calculated fitness function values are compared, and the optimal quality of the counterweight itself and the global optimal quality are recorded.

(5) Determining whether the global optimal weight quality within the allowed range is achieved: if it is, the result is output; if not, continue to the next step.

(6) Updating the weight mass according to the initial flight speed and distance set, and the next flight speed and distance of the weight are changed; return to step (3) which can perform the next iteration until the optimal weight is obtained.

\section{Simulation Analysis of the Spindle Rotor System}

3.1. The Calculation of Modal Simulation. According to the self-balancing spindle rotor system independently developed, the rotor system model is established. The rotor system is supported through the front and rear bearing. The front bearing and rear bearing are 7012 and 7009 angular contact ball bearings, respectively. The specific parameters of rotor system are shown in Table 1.

Before the modal analysis of the spindle rotor system, it is necessary to discretize the bearing rotor model unit, through meshing method. It is significant to select a reasonable meshing method, which can affect the analysis process and results of modal analysis. In the paper, 6-hedral division method is used in the front bearing, and 4-hedral division method is adopted in the rear bearing. The shaft is also divided according to the size of each step. The mesh division effect diagram of the spindle rotor system is shown in Figure 3.

The dynamic balance head is installed in the cavity of the front end in the spindle rotor system, which can realize the online dynamic balance. The rotor system model is 


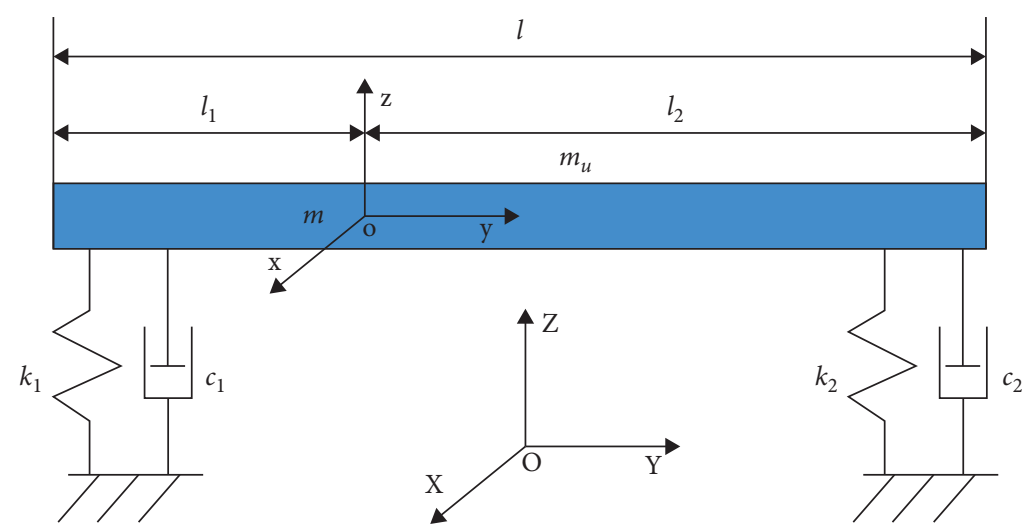

Figure 1: The force diagram of spindle rotor system.

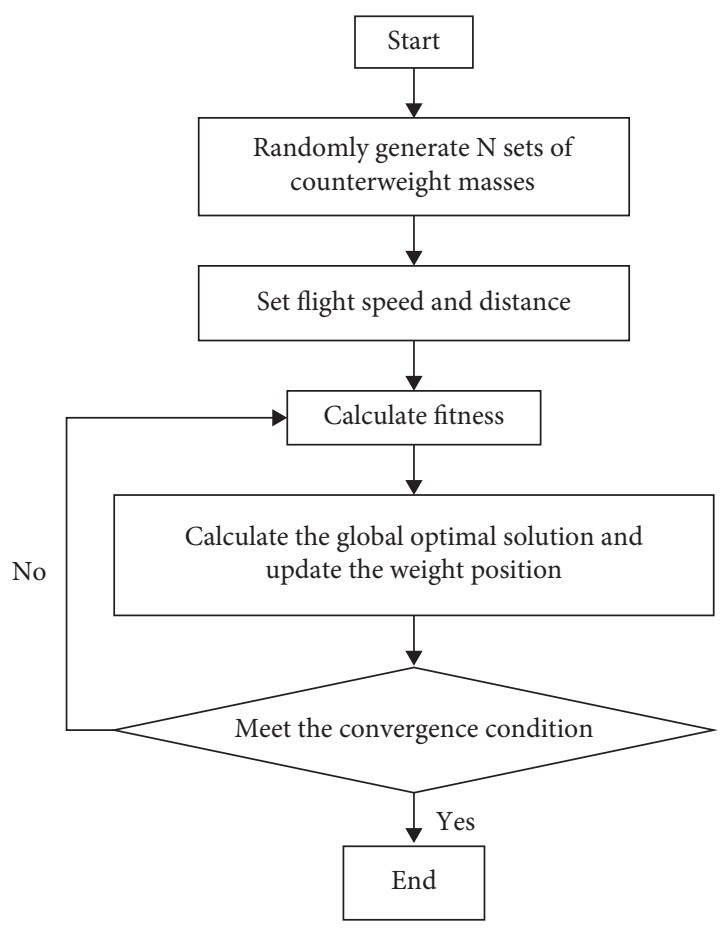

FIgURE 2: The chart of particle swarm algorithm.

TABLE 1: The specific parameters of rotor system.

\begin{tabular}{lc}
\hline Parameter & Size \\
\hline Length of rotor & $400 \mathrm{~mm}$ \\
Diameter of rotor & $57 \mathrm{~mm}$ \\
Inner diameter of rotor & $24 \mathrm{~mm}$ \\
Diameter of disk & $100 \mathrm{~mm}$ \\
Thickness of disk & $150 \mathrm{~mm}$ \\
Mass of disk & $9.24 \mathrm{~kg}$ \\
Elastic modulus & $E=2.1 \times 1011$ \\
\hline
\end{tabular}

calculated and analyzed through finite element software. The first- and second-order vibration mode of the rotor system are obtained, as shown in Figure 4 . It can be seen that the rotor system has the largest deformation near the two bearings, so the front and rear contacting end area are taken

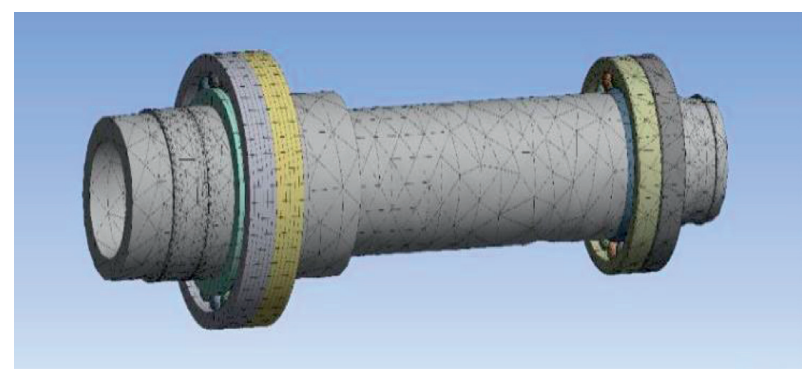

FIgURE 3: The mesh division effect diagram of the spindle rotor system.

as the correcting area of the unbalance amount. The first two main modes of the rotor system are $[0.742,0.742 ; 0.459$, $0.170]$.

Due to the increasing speed, the centrifugal inertia force and flexible deformation of the rotor obviously affect the vibration. Compared with the first-order vibration mode, the second-order vibration mode of the rotor system has bending deformation, and the deformation degree increases by $33.15 \%$.

The Campbell diagram of rotor system can be obtained by modal analysis. The critical speed of rotor system can be received from Campbell diagram. The first-order speed and second-order speed of rotor system are $6006.4 \mathrm{r} / \mathrm{min}$ and $22060.6 \mathrm{r} / \mathrm{min}$, respectively. Because rotor system will vibrate strongly near the critical speed, it is necessary to avoid the critical speed in the experiment. $6000 \mathrm{r} / \mathrm{min}$ is close to the critical speed which is selected as the balance speed. The experimental speed starts from $2000 \mathrm{r} / \mathrm{min}$, and the experimental speed is recorded every $2000 \mathrm{r} / \mathrm{min}$ until $24000 \mathrm{r} / \mathrm{min}$. The dynamic balance of the rotor system is studied from different speed.

3.2. The Calculation of Dynamic Balance. It is assumed that the established rotor model has no unbalance under ideal conditions; an unbalance mass block is added to the front end of the rotor system to simulate the unbalance effect. The proposed particle swarm optimization method is applied to balance the spindle rotor system in the balance simulation, and the process can be used to check the rationality of the 

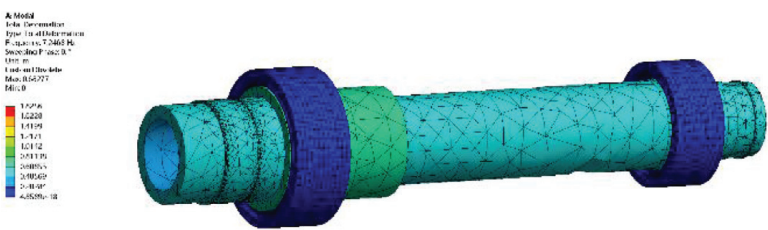

(a)
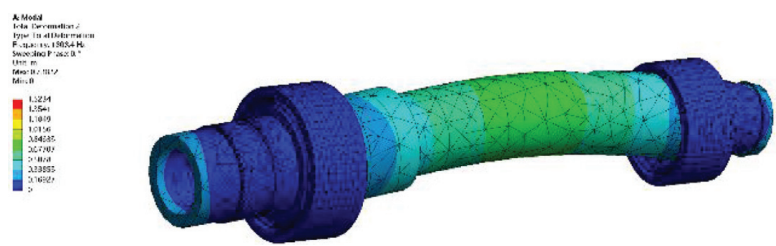

(b)

FIgURE 4: Vibration mode of bearing rotor. (a) First-order vibration mode. (b) Second-order vibration mode.

counterweight block which is obtained by the optimization method. The front and rear end of the rotor system can be used as a balance correction surface. The method of adding unbalance amount block in the end of the rotor system is adapted. The three kinds of unbalance, $5 \mathrm{~g} \cdot \mathrm{mm}, 10 \mathrm{~g} \cdot \mathrm{mm}$, and $15 \mathrm{~g} \cdot \mathrm{mm}$, are added, and the phase is $0^{\circ}, 90^{\circ}$, and $180^{\circ}$, respectively. Then the first two modes of the rotor system are obtained by modal analysis. According to the balance conditions of the modal balance method, the correction amount needed to be added on the balance correction surface can be calculated. After that the optimized balance of the rotor system needs to be carried out. The optimized balance is to calculate the weight of the balanced counterweight block through the particle swarm optimization. The correction and phase of unbalance mass of the spindle rotor system in $5 \mathrm{~g} \cdot \mathrm{mm}, 10 \mathrm{~g} \cdot \mathrm{mm}$, and $15 \mathrm{~g} \cdot \mathrm{mm}$ can be obtained, as shown in Tables 2-4, respectively. From the three tables, the weight mass and phase required for balancing the rotor system at different unbalance levels can be seen.

The vibration amplitudes of rotor system can be obtained through the above tables, which is shown in Figures 5-7. The vibration amplitude of the rotor system without balance, which fluctuates greatly at $6000 \mathrm{r} / \mathrm{min}$ and $22000 \mathrm{r} / \mathrm{min}$, is demonstrated in Figure 5. The dynamic balance is a very important vibration factor of rotor system, so this section will mainly study the influence of dynamic balance on the dynamic behavior. From Figure 6, it can be exhibited that the average dynamic balance rate is $64.87 \%$ through rotor system balancing. And the maximum balance rate is $71.27 \%$ at the condition that the speed is $20000 \mathrm{r} / \mathrm{min}$ and the unbalance is $5 \mathrm{~g} \cdot \mathrm{mm}$.

The amplitude of the rotor system through optimized balance is shown in Figure 7. It can be found that the effect of optimized balancing on rotor system is significant. Therefore, it is very necessary to study the influence of PSO algorithm on the balance of rotor system. The average balance rate is $72.38 \%$ through optimized balance. When the speed is $6000 \mathrm{r} / \mathrm{min}$ and the unbalance is $10 \mathrm{~g} \cdot \mathrm{mm}$, the maximum balance rate of the optimized rotor system amplitude is $75.88 \%$. What is more, compared with the modal balance method, the maximum vibration amplitude decreased by $34.75 \%$, and the average amplitude decreased by $21.23 \%$.

When the unbalance amount is $10 \mathrm{~g} \cdot \mathrm{mm}$ and the speed is, respectively, at $6000 \mathrm{r} / \mathrm{min}$ and $22000 \mathrm{r} / \mathrm{min}$, the axis movement trajectories of the rotor system in three cases are shown in Figure 8.

Thus, in Figure $8(\mathrm{a})$, the axis movement trajectories without balance, modal balance, and balanced modal based on particle swarm optimization can be seen corresponding to trajectories radius of $24.41 \mu \mathrm{m}, 9.07 \mu \mathrm{m}$, and $5.93 \mu \mathrm{m}$, respectively. The results of trajectories diagrams show that the optimized balance method effect on the rotor system is obvious. From Figure 8(b), the speed has a great influence on the balance of the rotor system. With the increase in rotational speed, the influence of movement trajectories on the dynamic characteristics of spindle rotor system began to be large. In the high speed range, compared with the low speed, that of the trajectories radius is $30.68 \mu \mathrm{m}, 10.52 \mu \mathrm{m}$, and $8.48 \mu \mathrm{m}$; the response of rotor system evolves from strong vibration and centrifugal effect.

The frequency domain is also a good way to observe in cover low-rising periodic signal; the fundamental frequency signal represents the state of unbalance vibration of spindle rotor system. The frequency domain of the spindle rotor system is shown in Figure 9. The fundamental frequency value of the rotor system decreased obviously through optimized balance. When the speed is $6000 \mathrm{r} / \mathrm{min}$, through PSO balance method, the amplitude of the frequency domain compared with balance modal method and without balance decreased by $39.68 \%$ and $44.66 \%$. The results show that the rotor system balancing method based on particle swarm optimization is effective.

\section{Experimental Verification}

4.1. Setting Up Experimental Platform. The dynamic balance experimental platform consists of spindle (HT-170-11), data collector (MRBB47), and laser vibrometer (OFV-505/5000), which is shown in Figure 10. The front and rear ends of the spindle can be added mass blocks; the specific parameters of the spindle are shown in Table 5. The vibration of the spindle is measured through laser vibrometer under different conditions, which illuminates the front end of the spindle based on Doppler effect. The speed selection range of spindle is $4000-24000 \mathrm{rpm}$, and every speed interval is $2000 \mathrm{r} / \mathrm{min}$. Due to the high speed of motorized spindle, the protective device is adopted in the experimental platform.

Unbalance mass of $5 \mathrm{~g} \cdot \mathrm{mm}, 10 \mathrm{~g} \cdot \mathrm{mm}$, and $15 \mathrm{~g} \cdot \mathrm{mm}$ is added at the front end of spindle, with initial phases of $0^{\circ}$, $90^{\circ}$, and $180^{\circ}$, respectively. And the first two order modes of the spindle rotor system are $[0.742,0.742 ; 0.459,0.170]$. The unbalance correction and phase of the spindle rotor system at $5 \mathrm{~g} \cdot \mathrm{mm}, 10 \mathrm{~g} \cdot \mathrm{mm}$, and $15 \mathrm{~g} \cdot \mathrm{mm}$ can be obtained, as shown in Tables 6-8.

The experiment vibration amplitude comparison diagram of spindle rotor system under different conditions is 
TABLE 2: Simulation data of $5 \mathrm{~g} \cdot \mathrm{mm}$ unbalanced mass.

\begin{tabular}{|c|c|c|c|c|c|c|c|c|c|c|c|c|}
\hline Speed $(r / \mathrm{min})$ & 2000 & 4000 & 6000 & 8000 & 10000 & 12000 & 14000 & 16000 & 18000 & 20000 & 22000 & 24000 \\
\hline Initial amplitude $(\mu \mathrm{m})$ & 16.76 & 18.02 & 24.41 & 20.18 & 22.50 & 24.23 & 26.32 & 28.00 & 30.15 & 32.69 & 36.74 & 33.48 \\
\hline $\begin{array}{lc}\text { Correction value } & \text { Front end } \\
(\mathrm{g} \cdot \mathrm{mm}) & \text { Rear end }\end{array}$ & \multicolumn{12}{|c|}{$\begin{array}{l}3.96 \angle 180^{\circ} \\
10.70 \angle 0^{\circ}\end{array}$} \\
\hline $\begin{array}{l}\text { Amplitude after balance }(\mu \mathrm{m}) \\
\text { Optimize correction amount } \\
(\mathrm{g} \cdot \mathrm{mm}) \\
\text { Front end } \\
\text { Rear end }\end{array}$ & \multicolumn{12}{|c|}{$\begin{array}{l}3.81 \angle 180^{\circ} \\
10.55 \angle 0^{\circ}\end{array}$} \\
\hline Amplitude after optimized balance $(\mu \mathrm{m})$ & 4.04 & 4.36 & 5.93 & 5.19 & 5.96 & 6.44 & 6.88 & 7.60 & 8.06 & 8.65 & 11.43 & 9.64 \\
\hline
\end{tabular}

TABLE 3: Simulation data of $10 \mathrm{~g} \cdot \mathrm{mm}$ unbalanced mass.

\begin{tabular}{|c|c|c|c|c|c|c|c|c|c|c|c|c|}
\hline Speed $(r / \mathrm{min})$ & 2000 & 4000 & 6000 & 8000 & 10000 & 12000 & 14000 & 16000 & 18000 & 20000 & 22000 & 24000 \\
\hline Initial amplitude $(\mu \mathrm{m})$ & 17.62 & 19.40 & 25.19 & 21.22 & 23.28 & 25.15 & 27.39 & 29.42 & 31.13 & 33.27 & 39.10 & 35.79 \\
\hline $\begin{array}{lc}\text { Correction value } & \text { Front end } \\
(\mathrm{g} \cdot \mathrm{mm}) & \text { Rear end }\end{array}$ & \multicolumn{12}{|c|}{$\begin{array}{l}7.93 \angle 270^{\circ} \\
21.40 \angle 90^{\circ}\end{array}$} \\
\hline Amplitude after balance $(\mu \mathrm{m})$ & 5.47 & 6.41 & 9.58 & 6.88 & 7.89 & 9.00 & 9.48 & 9.84 & 10.90 & 13.87 & 17.15 & 14.45 \\
\hline $\begin{array}{lc}\text { Optimize correction amount } & \text { Front end } \\
(\mathrm{g} \cdot \mathrm{mm}) & \text { Rear end }\end{array}$ & \multicolumn{12}{|c|}{$\begin{array}{l}5.47 \angle 270^{\circ} \\
18.95 \angle 90^{\circ}\end{array}$} \\
\hline Amplitude after optimized balance $(\mu \mathrm{m})$ & 4.36 & 4.85 & 6.25 & 5.42 & 6.36 & 7.33 & 7.32 & 8.46 & 9.07 & 9.92 & 12.63 & 10.36 \\
\hline
\end{tabular}

TABLE 4: Simulation data of $15 \mathrm{~g} \cdot \mathrm{mm}$ unbalanced mass.

\begin{tabular}{|c|c|c|c|c|c|c|c|c|c|c|c|c|}
\hline Speed $(r / \mathrm{min})$ & 2000 & 4000 & 6000 & 8000 & 10000 & 12000 & 14000 & 16000 & 18000 & 20000 & 22000 & 24000 \\
\hline Initial amplitude $(\mu \mathrm{m})$ & 18.99 & 20.82 & 26.82 & 22.73 & 24.37 & 26.77 & 29.32 & 30.36 & 32.64 & 35.39 & 40.81 & 36.52 \\
\hline Correction value & \multirow{2}{*}{\multicolumn{12}{|c|}{$\begin{array}{c}11.89 \angle 0^{\circ} \\
32.12 \angle 180^{\circ}\end{array}$}} \\
\hline$(\mathrm{g} \cdot \mathrm{mm}) \quad$ Rear end & & & & & & & & & & & & \\
\hline Amplitude after balance $(\mu \mathrm{m})$ & 6.24 & 6.78 & 9.99 & 7.22 & 8.51 & 9.39 & 9.87 & 10.60 & 11.73 & 13.87 & 17.15 & 14.45 \\
\hline $\begin{array}{ll}\text { Optimize correction amount } & \text { Front end } \\
(\mathrm{g} \cdot \mathrm{mm}) & \text { Rear end }\end{array}$ & \multicolumn{12}{|c|}{$\begin{array}{c}9.71 \angle 0^{\circ} \\
29.93 \angle 180^{\circ}\end{array}$} \\
\hline Amplitude after optimized balance $(\mu \mathrm{m})$ & 4.75 & 5.37 & 7.01 & 6.02 & 6.84 & 7.92 & 8.12 & 9.02 & 9.67 & 10.56 & 14.13 & 11.64 \\
\hline
\end{tabular}

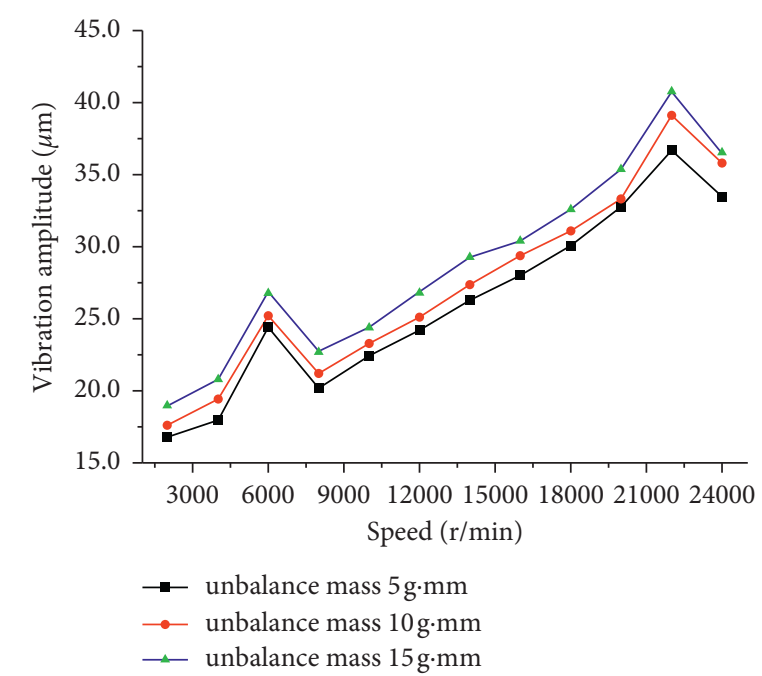

FIgURE 5: Amplitude of spindle rotor system without balance.

shown in Figures 11-13. It can be seen that the vibration amplitude fluctuates greatly at $6000 \mathrm{r} / \mathrm{min}$ and $22000 \mathrm{r} / \mathrm{min}$. This is because the speed of spindle is close to the critical speed. Figure 11 shows that the maximum vibration of the rotor system is emerged in $22000 \mathrm{r} / \mathrm{min}$, which means that it is a synchronous response with the natural frequency. In 


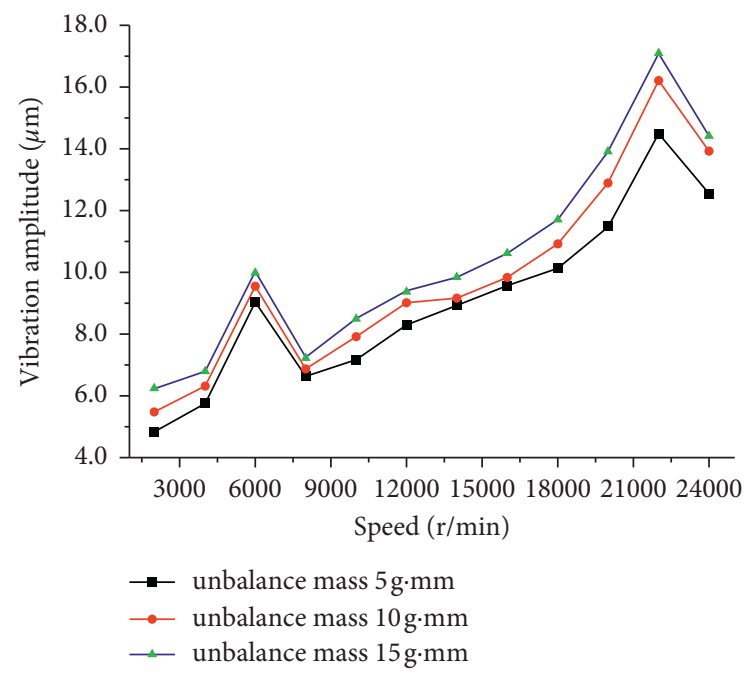

FIGURE 6: Amplitude of spindle rotor system with balance.

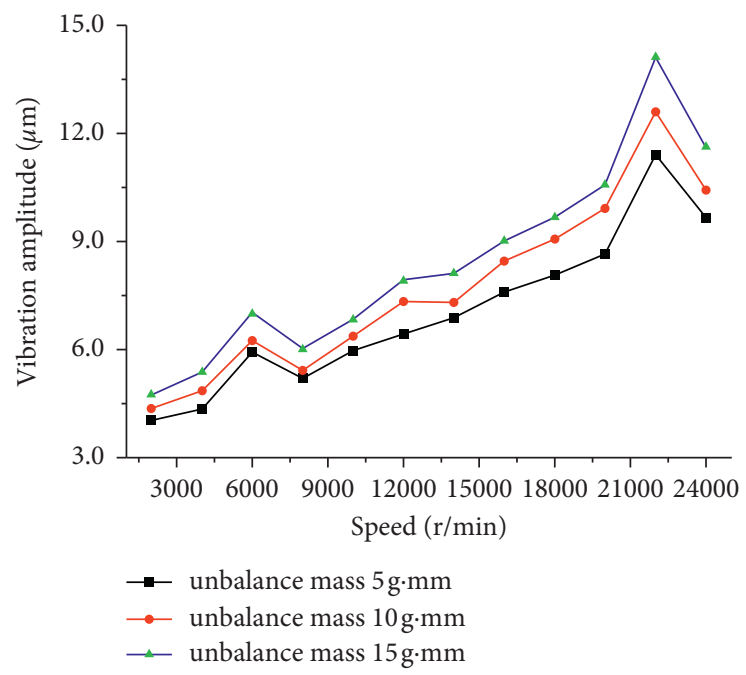

FIgURE 7: Amplitude of spindle rotor system with optimized balance.

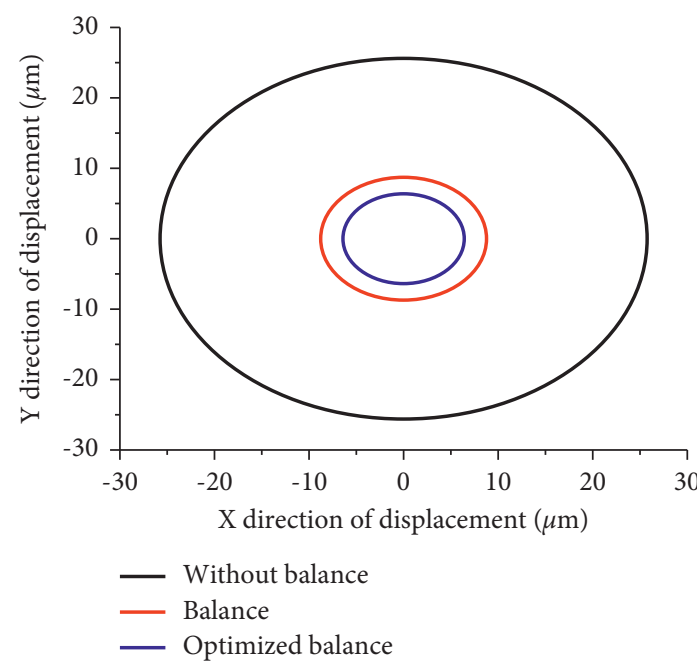

(a)

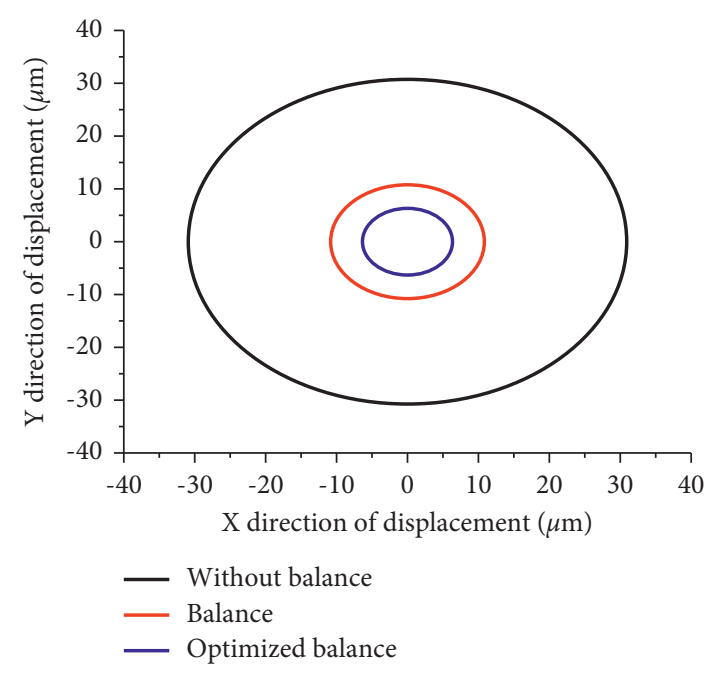

(b)

Figure 8: The axis movement trajectories of spindle rotor system. (a) The speed is $6000 \mathrm{r} / \mathrm{min}$. (b) The speed is $22000 \mathrm{r} / \mathrm{min}$. 


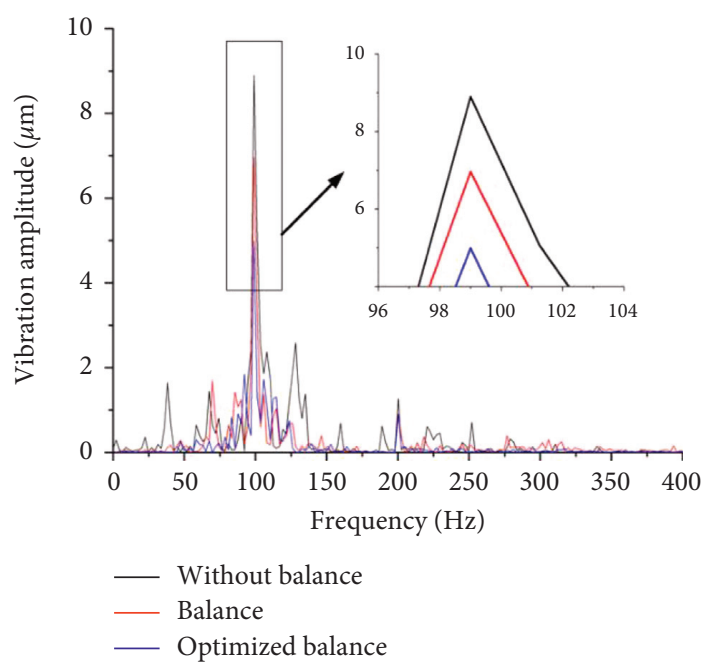

Figure 9: The frequency domain of the spindle rotor system.

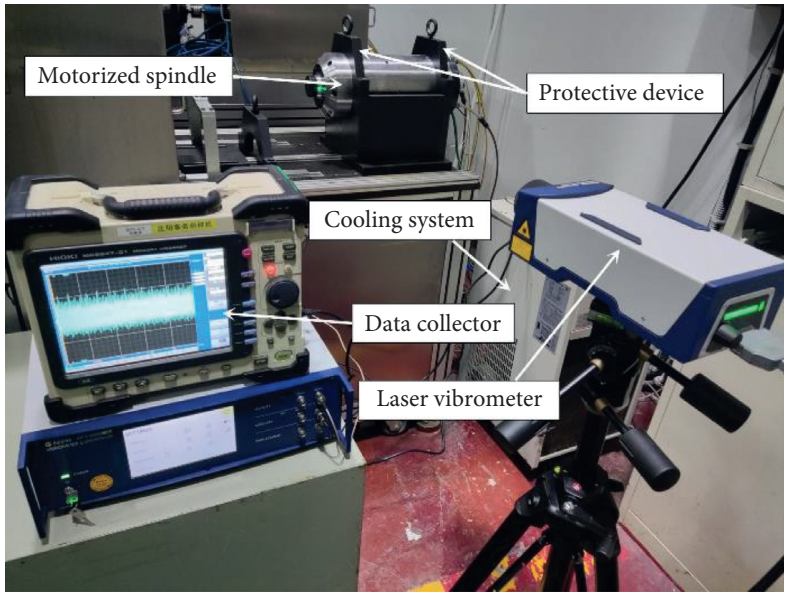

FIgURE 10: The dynamic balance experimental platform.

TABle 5: The specific parameters of spindle.

\begin{tabular}{lc}
\hline Parameter & Size \\
\hline Axial length & $400 \mathrm{~mm}$ \\
Radius of the rotor & $50 \mathrm{~mm}$ \\
Modulus of elasticity & $E=2.1 \times 1011$ \\
Frequency & $500 \mathrm{~Hz}$ \\
Current & $22.3 \mathrm{~A}$ \\
Front bearing & 7012 angular contact ball bearings \\
Rear bearing & 7009 angular contact ball bearings \\
Cooling & Water cooling \\
Lubrication & Oil and gas lubrication \\
Logarithm of motor poles & 2 \\
Power & $11 \mathrm{~kW}$
\end{tabular}

addition, this phenomenon indicates that the influence of nonlinear vibration caused by unbalance mass and speed begins to increase gradually.

In Figure 12, the results show that the modal balance method has an obvious influence on the rotor system vibration. It can be seen that the vibration of the rotor system causes decreasing phenomenon especially at high speed. And the decreasing average value of vibration is $64.3 \%$ at the condition of $5 \mathrm{~g} \cdot \mathrm{mm}$ unbalance mass. Besides, spindle rotor system has a marked improvement of the dynamic behavior.

Figure 13 depicts a diagram for experiment vibration amplitude of spindle rotor system with optimized balance. 
TABle 6: Experimental data of $5 \mathrm{~g} \cdot \mathrm{mm}$ unbalanced mass.

\begin{tabular}{|c|c|c|c|c|c|c|c|c|c|c|c|c|}
\hline \multicolumn{2}{|l|}{ Rotating speed $/ r / \mathrm{min}$} & 4000 & 6000 & 8000 & 10000 & 12000 & 14000 & 16000 & 18000 & 20000 & 22000 & 24000 \\
\hline \multicolumn{2}{|c|}{ Initial amplitude $/ \mu \mathrm{m}$} & 18.5 & 25.9 & 20 & 23.1 & 23.6 & 25.8 & 28.7 & 30.6 & 32.2 & 37.1 & 34.5 \\
\hline $\begin{array}{l}\text { Correction value } \\
(\mathrm{g} \cdot \mathrm{mm})\end{array}$ & $\begin{array}{l}\text { Front end } \\
\text { Rear end }\end{array}$ & \multicolumn{11}{|c|}{$\begin{array}{l}8.32 \angle 180^{\circ} \\
22.48 \angle 0^{\circ}\end{array}$} \\
\hline \multicolumn{2}{|c|}{ Amplitude after balance $(\mu \mathrm{m})$} & 4.95 & 6.53 & 5.53 & 6.55 & 7.57 & 8.23 & 8.93 & 9.3 & 10.1 & 12.8 & 10.6 \\
\hline $\begin{array}{l}\text { Optimize correction amount } \\
(\mathrm{g} \cdot \mathrm{mm})\end{array}$ & $\begin{array}{l}\text { Front end } \\
\text { Rear end }\end{array}$ & \multicolumn{11}{|c|}{$\begin{array}{l}6.81 \angle 180^{\circ} \\
19.96 \angle 0^{\circ}\end{array}$} \\
\hline Amplitude after optimization & & 4.86 & 6.44 & 5.39 & 6.29 & 6.74 & 7.26 & 7.76 & 8.56 & 8.74 & 11.6 & 9.95 \\
\hline
\end{tabular}

TABLE 7: Experimental data of $10 \mathrm{~g} \cdot \mathrm{mm}$ unbalanced mass.

\begin{tabular}{|c|c|c|c|c|c|c|c|c|c|c|c|}
\hline Rotating speed $/ r / \mathrm{min}$ & 4000 & 6000 & 8000 & 10000 & 12000 & 14000 & 16000 & 18000 & 20000 & 22000 & 24000 \\
\hline Initial amplitude/ $\mu \mathrm{m}$ & 19.6 & 26.5 & 20.6 & 24 & 25.6 & 27.5 & 30.1 & 31.4 & 33.7 & 38.2 & 36.2 \\
\hline Correction value/g.mm & \multicolumn{11}{|c|}{$\begin{array}{l}16.64 \angle 270^{\circ} \\
44.95 \angle 90^{\circ}\end{array}$} \\
\hline Amplitude after balance $/ \mu \mathrm{m}$ & 6.92 & 10.59 & 7.05 & 8.27 & 9.43 & 9.6 & 10.32 & 11.1 & 12.7 & 16.4 & 14.3 \\
\hline $\begin{array}{ll}\text { Optimize correction amount/ } & \text { Front end } \\
\text { g.mm } & \text { Rear end }\end{array}$ & \multicolumn{11}{|c|}{$\begin{array}{l}14.08 \angle 270^{\circ} \\
42.38 \angle 90^{\circ}\end{array}$} \\
\hline Amplitude after optimization $/ \mu \mathrm{m}$ & 4.95 & 6.53 & 5.53 & 6.55 & 7.57 & 8.23 & 8.93 & 9.3 & 10.1 & 12.8 & 10.6 \\
\hline
\end{tabular}

TABLE 8: Experimental data of $15 \mathrm{~g} \cdot \mathrm{mm}$ unbalanced mass.

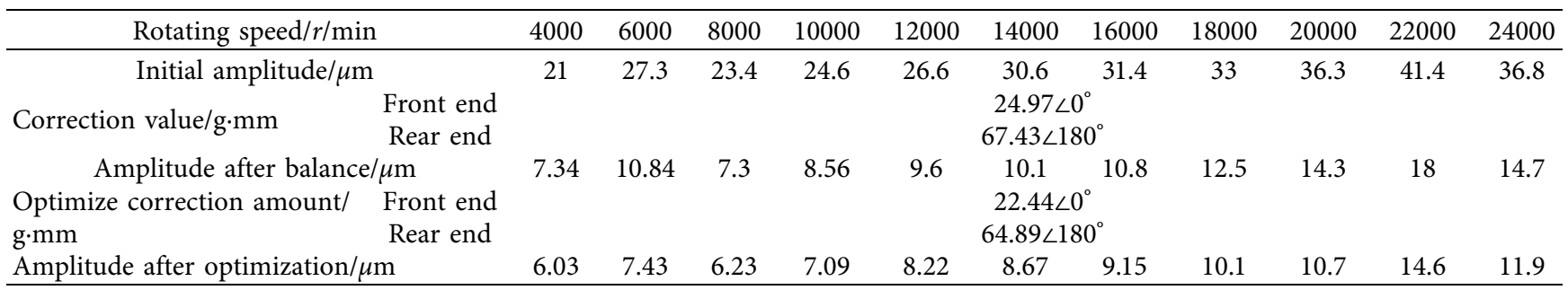

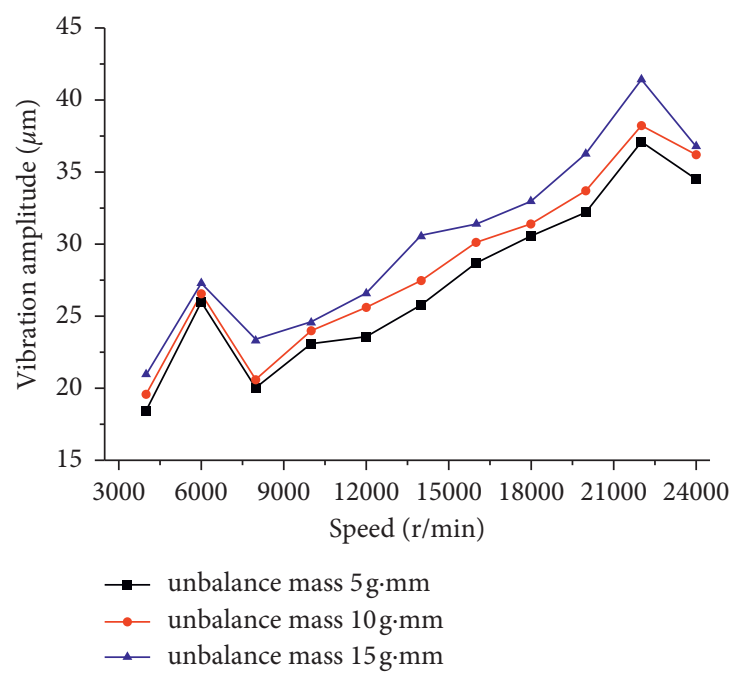

FIGURE 11: Experiment vibration amplitude of spindle rotor system without balance.

Compared with Figures 11 and 12, it indicates that the change trend of the vibration curve is basically the same with them. However, it is found that the vibration curve is relatively small through PSO balance, which can effectively suppress the vibration caused by rotor imbalance.
At the condition of unbalance mass of $15 \mathrm{~g} \cdot \mathrm{mm}$, a comprehensive view of the effect of the PSO balance on the spindle rotor system is given in Figure 14.

As can be seen, the vibration of the rotor system without balance is much larger than other conditions, in which the 


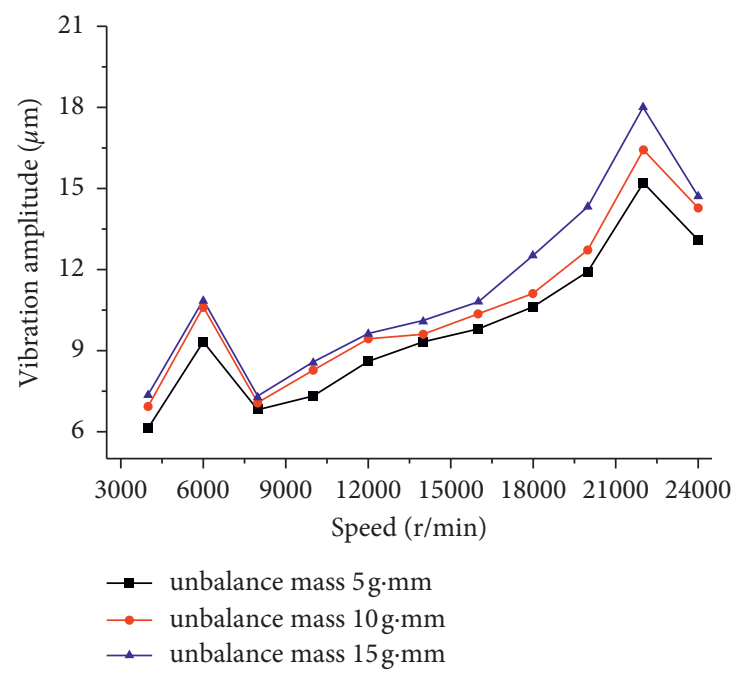

Figure 12: Experiment vibration amplitude of spindle rotor system with balance.

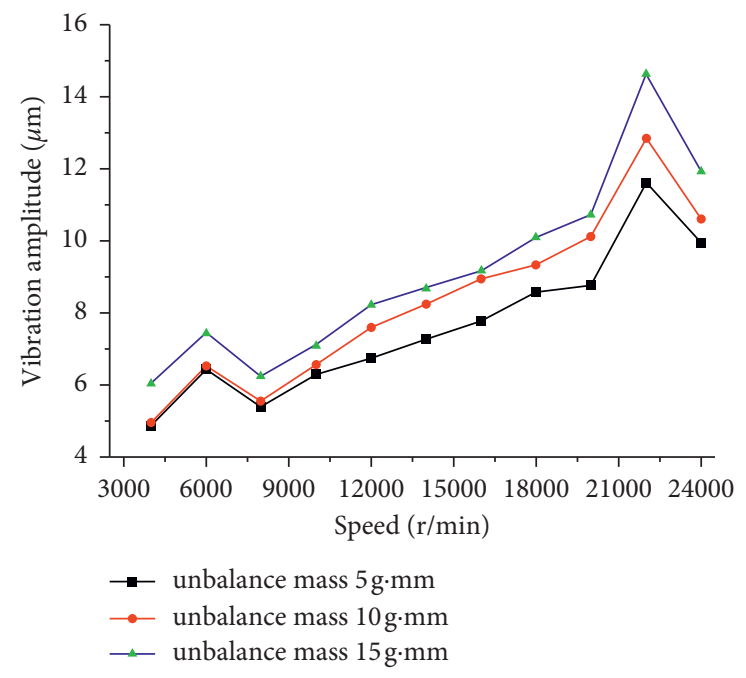

FIGURE 13: Experiment amplitude of spindle rotor system with optimized balance.

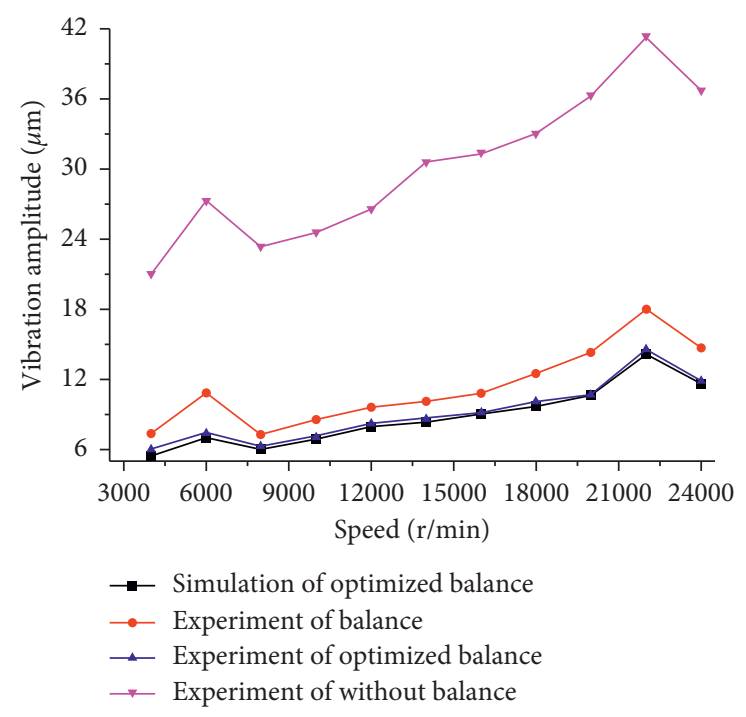

FIgURE 14: Simulation and experiment of rotor system vibration amplitude. 
maximum amplitude exceeds $41 \mu \mathrm{m}$. The good news is that the dynamic behavior of the rotor system is improved through dynamic balance. Besides, the PSO optimization algorithm is applied in the modal balance. Note that the simulation and experimental average error is $4 \%$ through optimized balance. The results can give a better explanation to the PSO optimization algorithm existence of improving the spindle rotor system dynamic characteristics.

\section{Conclusion}

The PSO dynamic modal balance has been applied in the nonlinear dynamic behavior of spindle rotor system which have been presented in this paper. The PSO dynamic modal balance model is established to suppress vibration. The spindle rotor system before or after dynamic balance is obtained through dynamic model. The unbalance response of different unbalance mass was studied. The results reveal that, through PSO dynamic modal balance, the vibration amplitude is smaller than that without balance or dynamic modal balance. As the speed increases, the PSO dynamic modal balance method has an obvious effect on improving the dynamic characteristics of rotor system. And the stability and accuracy of dynamic balance model were verified through different experiments, and the average error is $4 \%$. Therefore, to avoid the strong vibration in the spindle rotor system, the investigation on the dynamic balance based on the PSO method is of great significance during the operation stage.

\section{Data Availability}

The data used to support the findings of this study are available from the corresponding author upon request.

\section{Conflicts of Interest}

The authors declare that they have no conflicts of interest.

\section{Acknowledgments}

This work was supported by the National Natural Science Foundation of China (51805337), the Key Laboratory of Vibration and Control of Aero-Propulsion System, Ministry of Education (VCAME202008), the Scientific Research Project of Liaoning Provincial Education Department (lnjc202010), and the Youth Science and Technology Innovation Project (2021-HJQZ-08).

\section{References}

[1] A. Das, S. Shukla, M. Kumar, C. Singh, M. L. Chandravanshi, and V. Bajpai, "Development of a vibration free machine structure for high-speed micro-milling center," International Journal of Advanced Manufacturing Technology, vol. 116, no. 11-12, pp. 3489-3506, 2021.

[2] Z. Wang, K. Zhang, Z. Wang, X. Bai, and Q. Wang, "Research on vibration of ceramic motorized spindle influenced by interference and thermal displacement," Journal of Mechanical Science and Technology, vol. 35, no. 6, pp. 2325-2335, 2021.
[3] I. Vojtko, P. Baron, M. Pollák, and J. Kaščak, "Examining the effect of alignment of the rotor of the emissions exhaust fan on its operating parameters," Advances in Materials Science and Engineering, vol. 2019, pp. 1-13, 2019.

[4] K. Zhang, Z. N. Wang, X. T. Bai, H. T. Shi, and Q. Wang, “The effect of preload on the dynamic characteristics of ceramic bearings based on a dynamic thermal coupling model," Advances in Mechanical Engineering, vol. 12, pp. 1-18, 2020.

[5] S. H. Zhang and Z. M. Zhang, "A method to select correcting faces of a double-face dynamic balancing rotor," Advances in Mechanical Engineering, vol. 8, pp. 1-9, 2016.

[6] J. Huang, X. M. Ren, and W. Q. Deng, "Novel modal balancing of flexible rotor by using the run-up amplitude," Journal of Mechanical Engineering, vol. 46, no. 5, pp. 55-62, 2010.

[7] G. R. Wen, T. P. Zang, and Y. H. Liao, "Transient balancing of rotor based on non-stationary information," Journal of Vibration, Measurement and Diagnosis, vol. 33, pp. 614-619, 2013.

[8] H. Chen, L. Hou, Y. Chen, and R. Yang, "Dynamic characteristics of flexible rotor with squeeze film damper excited by two frequencies," Nonlinear Dynamics, vol. 87, no. 4, pp. 2463-2481, 2017.

[9] M. B. Deepthikumar, A. S. Sekhar, and M. R. Srikanthan, "Modal balancing of flexible rotors with bow and distributed unbalance," Journal of Sound and Vibration, vol. 332, no. 24, pp. 6216-6233, 2013.

[10] W. Zhou, Y. Cao, N. Zhang, B. Gao, N. Qiu, and W. Zhang, "A novel axial vibration model of multistage pump rotor system with dynamic force of balance disc," Journal of Vibration Engineering \& Technologies, vol. 8, no. 5, pp. 673-683, 2020.

[11] G. Bin, X. J. Li, Y. P. Shen, and J. J. Gao, "Whole-machine dynamic balancing method without trial weights for multispan rotor shafting based on dynamic finite element model," Journal of Mechanical Engineering, vol. 52, no. 21, pp. 78-86, 2016.

[12] X. M. Tao, W. J. Guo, Q. Li, C. Ren, and R. Liu, "Multiple scale self-adaptive cooperation mutation strategy-based particle swarm optimization," Applied Soft Computing Journal, vol. 89, pp. 01-18, 2020.

[13] X. L. Yun, Z. K. Pang, G. D. Jiang, and X. S. Mei, "Research on identification of unbalance parameters of rotor with multiplane using improved particle swarm optimization," Journal of the Brazilian Society of Mechanical Sciences and Engineering, vol. 43, pp. 1-12, 2021.

[14] L. Max, L. Bernd, and E. Ulrich, "Residual modal unbalance evaluation method by mode shape weighted optimization," Mechanisms and Machine Science, vol. 63, pp. 93-108, 2019.

[15] X. F. Li, L. X. Zheng, and Z. X. Liu, "Theoretical and experimental research on balancing of flexible rotors without trial weights," Vibration Test and Diagnosis, vol. 33, pp. 65570, 2013.

[16] R. A. F. Díaz, J. E. Aguirre Romano, A. Cruz Alcantar, and P. C. Alcantar, "Methodology to improve mode identification and modal parameter extraction for rotor dynamic analysis," Journal of Vibroengineering, vol. 19, no. 4, pp. 2806-2821, 2017.

[17] M. Usman, W. Pang, and G. M. Coghill, "Inferring structure and parameters of dynamic system models simultaneously using swarm intelligence approaches," Memetic Computing, vol. 12 , no. 3 , pp. 267-282, 2020.

[18] R. Lmalghan, K. Rao M C, S. ArunKumar, S. S. Rao, and M. A. Herbert, "Machining parameters optimization of AA6061 using response surface methodology and particle 
swarm optimization," International Journal of Precision Engineering and Manufacturing, vol. 19, no. 5, pp. 695-704, 2018.

[19] A. Chowdhury, H. Zafar, B. K. Panigrahi, K. R. Krishnanand, A. Mohapatra, and Z. Cui, "Dynamic economic dispatch using Lbest-PSO with dynamically varying sub-swarms," Memetic Computing, vol. 6, no. 2, pp. 85-95, 2014.

[20] K. Zhang, Z. Wang, H. Shi, X. Bai, and Z. Wang, "Research on vibration characteristics of a ceramic spindle based on the reverse magnetic effect," Shock and Vibration, vol. 2019, pp. 1-15, 2019. 